\title{
SOBRE RATOEIRA E WORLD MUSIC: MÚSICA E RELAÇÕES DE GÊNERO EM FLORIANÓPOLIS.
}

\section{Maria Ignez Cruz Mello*, Letícia Grala Dias**}

As representações da subjetividade feminina na música, bem como a reprodução do modelo da masculinidade no código musical têm sido objetos de análise de vários autores, como Susan McClary (1991), Krammer (1990), Citron (1993), Cusick (1994), Walterman (1993), Mello (2006) entre outros. Estes estudos analisam composições, arranjos e interpretações femininas a fim de perceber de que forma a subjetividade das mulheres que se envolvem com a produção musical alcança sua expressão. Outros estudos, como Diniz (1949), Kater (2001) e Holanda (2006), trazem à luz trabalhos de compositoras que, devido à forte dominação masculina, não apareceram no cenário musical/social de sua época.

Com o intuito de investigar o impacto que as questões de gênero exercem na produção musical atual, buscou-se com o presente trabalho investigar a atuação de algumas mulheres no cenário musical da região de Florianópolis. Para tanto, procuramos conhecer suas escolhas musicais e apresentar estratégias das quais elas se valem para ocuparem um espaço onde ainda representam uma minoria. Assim sendo, foram realizadas observações de dois universos distintos: o Grupo de Convivência do Ribeirão da Ilha e o Grupo Vocal Andara, ambos formados exclusivamente por mulheres. Tais observações se deram tanto durante ensaios quanto em apresentações, e também foram realizadas entrevistas com algumas das participantes de cada grupo.

Este trabalho segue a orientação da metodologia qualitativa de pesquisa, no sentido de enfatizar as especificidades de um fenômeno ao levar em consideração fatores como as origens e razão de ser do objeto em estudo, além de valorizar o ponto de vista dos sujeitos participantes (HAGUETTE, 1992). Essa orientação tem como uma de suas bases principais a preocupação com o processo, que é muito mais importante do que o produto final, perspectiva em que os sujeitos têm atenção especial do pesquisador.

\footnotetext{
${ }^{\square}$ Doutora em Antropologia Social e Professora do Departamento de Música da Universidade do Estado de Santa Catarina (UDESC). Endereço institucional: Centro de Artes, Av. Madre Benvenuta, 1907, 99.035001 Florianópolis - SC.Tel.: (048) 3231-9747. E-mail: migmello@ig.com

$\square$ * Acadêmica do curso de Música - CEART/UDESC, bolsista de iniciação científica UDESC/PROBIC. E-mail: legrala1@yahoo.com.br
} 


\title{
O Grupo de Convivência do Ribeirão da Ilha
}

Este grupo é formado por cerca de trinta "senhoras da terceira idade" e existe há mais de 30 anos.

Segundo elas, alguns homens também participaram do grupo, mesmo assim, em número reduzido. Depois destes, não houve mais participantes homens e, hoje em dia, muitas delas não desejam a participação masculina, pois alegam que não há atividades no grupo para eles e elas sentem-se mais à vontade só entre mulheres.

Um aspecto interessante observado durante nossos encontros foi a autonomia do grupo: mesmo que algumas delas exerçam maior liderança, a opinião de todas sempre foi solicitada nas decisões a serem tomadas. Elas próprias decidem se querem/podem aceitar convites de eventos e promover atividades.

Percebe-se que os encontros das senhoras do Ribeirão da Ilha têm como sua principal função promover atividades nas quais as participantes possam se inserir no meio social de forma mais ativa. Ou seja, nesses encontros são planejados passeios, ensaios para participação em eventos ${ }^{1}$ e para cantar na "missa" ${ }^{2}$, festas nas quais às vezes executam a Ratoeira, entre outras atividades.

Tomamos como objeto de reflexão a "Ratoeira" contada a partir da experiência dessas senhoras, tanto na forma como era praticada em sua juventude como hoje, na velhice, e também a partir de breve revisão bibliográfica. A Ratoeira é uma manifestação cultural de origem açoriana que se configurou de forma específica em Florianópolis. Daniela Bunn, citando o historiador catarinense e professor da UFSC, Vilson Francisco de Farias, diz que esse autor:

\begin{abstract}
designa essa como uma cultura de base açoriana catarinense devido às modificações provocadas na cultura local, em meados do século XVIII, pelos imigrantes vindo dos Açores. Ao mesmo tempo em que adquiriam novos hábitos, os açorianos influenciavam os habitantes locais com sua vivência, [...] desde que dois grupos culturais entrem em contato surgem desde logo modificações e visões/olhares sobre a cultura do grupo oposto. (2006, p. 2)
\end{abstract}

Da mesma forma, Silva (2005) diz que a cultura açoriana do litoral catarinense deve ser entendida como "um caldeamento de culturas, uma história crioula" (p. 21).

Um dos aspectos da cultura açoriana local, ressaltado por Silva e apurado neste trabalho, é o universo "bruxólico" que, conforme esse autor é um aspecto importante na Ratoeira, por ser esta uma "prática musical eminentemente feminina". Diz que o “"bruxólico' caracteriza, com seu lado sobrenatural, um poder feminino informal dentro

\footnotetext{
O grupo já foi premiado com $2^{\circ}$ e $3^{\circ}$ lugares no Show de Talentos da Terceira Idade, festival promovido pela prefeitura de Florianópolis.

${ }^{2}$ Cantam na igreja católica algumas vezes.
} 
da sociedade" (op.cit. p. 26). Sobre o mundo "bruxólico" em Florianópolis, Maluf (1993) salienta que a bruxa aparece como uma figura transgressora. Quando as mulheres abandonam ocupações designadas socialmente a elas para adentrar em espaços considerado masculinos, é chamada de bruxa. Essa atitude transgressora das regras sociais pelas mulheres representa um perigo à autoridade masculina. Conforme a autora:

\begin{abstract}
A bruxa representa uma inversão dos papéis masculinos e femininos construídos pela sociedade, o que confere um poder às mulheres e ameaça a autoridade masculina (MALUF, 1993 apud Silva, 2005 p. 27).
\end{abstract}

Sendo cantada e dançada, a Ratoeira é uma brincadeira na qual, em roda, os participantes entoam versos improvisados ${ }^{3}$, intercalados por uma espécie de refrão onde todos cantam. Segundo relatos de algumas senhoras do Ribeirão, os versos eram destinados a um pretendente de namoro: "Hei, você que está tão longe/Venha aqui mais para perto/A minha vista está cansada/De te ver neste deserto".

Elas contam que hoje não se faz mais a Ratoeira com o intuito do namoro, como era no passado. Quando cantam, ou é para alguma apresentação ou para se divertirem apenas. Percebe-se então que a Ratoeira passou, ao longo dos anos, de interação amorosa entre jovens à manifestação artística, apresentando propósitos diferenciados da sua função original. Atualmente somente mulheres praticam a Ratoeira, configurando-se assim numa prática basicamente feminina.

Pôde-se perceber, portanto, que através desta ressignificação, a Ratoeira que na juventude destas mulheres era tida como uma forma de diversão atrelada ao namoro e à paquera, na velhice passou a ser vista como manifestação artística, e como forma de manterem-se inseridas e ativas na sociedade.

\title{
O Grupo Vocal Andara
}

Este é um grupo vocal formado por oito mulheres, na faixa dos quarenta anos, originado em Florianópolis. As integrantes vêm de diferentes lugares: Argentina, Uruguai e Brasil (RS e SC), e além das vozes, o grupo conta também com instrumentos de percussão como balafon, reco-reco, charango, tambor marroquino, ovinho, caxixi, pau-de-chuva, chocalho andino, pandeiro, tambor, castanholas, bumbo-leguero, xequerê, clavas, moringa, djambé, triângulo, repinique e também alternativos como

\footnotetext{
3 Os versos são chamados de improvisos, contudo, os participantes os sabem de cor. Existe um
} repertório de versos conhecidos pelos praticantes. 
"caixa sonora, peneira, chulé-fone".

A iniciativa de formar o grupo surgiu por parte de uma das integrantes que resolveu se articular e convidar pessoas que gostassem de cantar para fazerem um trabalho com canto. A partir daí surgiu o grupo Andara. Também relataram que já antes desse encontro algumas delas haviam formado um grupo coral na Costa de Dentro (bairro de Florianópolis). É interessante ressaltar que essa primeira formação do grupo vocal deu-se devido aos encontros que aconteceram em função de uma condição basicamente feminina que tinham em comum: todas eram mães e se reuniam em por causa dos filhos pequenos. Descobriram a partir desses encontros uma outra condição em comum: todas gostavam de cantar.

Segundo Silvia, uma das integrantes do grupo Andara, há grande afinidade musical com grupos como Anima (de Campinas -SP) e Mawaka (São Paulo - capital) que já possuem um espaço bem conquistado na mídia, tendo sido estes dois grupos as maiores influências estéticas do grupo.

No repertório do grupo Andara encontram-se músicas da tradição oral brasileira e também gêneros variados, numa fusão de estilos e sonoridades, assim como canções de culturas diversas. No repertório aparecem músicas como: Malaika (canção de ninar africana), Ojos Azules e Dona Ubenza (carnavalito argentino e baguala argentina), Fiandeiras (tradição oral brasileira), Mais de Oito (Comadre Fulozinha) - essas com arranjos realizados pela regente Vitória Aftalión, além de Manan Ciroua (canção haitiana) com arranjo de Geraldo Dirié. Desta forma, a música do grupo está fortemente ligada à reprodução, resgate e ressignificação de músicas étnicas, numa conformação que mescla, funde e une vários elementos de gêneros musicais e culturas diversas. Este tipo de fusão caracteriza o que atualmente vem sendo chamado de World Music.

Estas mulheres ressaltam que o objetivo do grupo não é o de realizar um trabalho comercial, mesmo que busquem estratégias para seu reconhecimento. As integrantes enfatizam que o objetivo do grupo é celebrar a vida, e procuram expressar com a música um compromisso com valores éticos e ideológicos de cada uma.

A partir do estudo destes grupos, pode-se inferir que as mulheres que os integram não seguem as regras de um mercado competitivo. Ambos os grupos fazem parte de um circuito não comercial de música, ligados a um imaginário de comunhão e fraternidade, entre membros de uma comunidade real (como as mulheres do Ribeirão) ou entre musicalidades do mundo todo (como as músicas do grupo Andara). Neste universo 
musical unplugged, acústico, que parece ir na contra-mão do mercado fonográfico, a força condutora vem da união de "energias femininas". A Word Music e a Ratoeira representam nesse caso, formas de expressão musical sustentadas tanto pela subjetividade feminina como pela força da cultura popular.

\section{REFERÊNCIAS BIBLIOGRÁFICAS:}

BUNN, D. Ratoeira bem cantada, manifestação popular. In: SEMINÁRIO INTERNACIONAL FAZENDO GÊNERO 7, 2006, Florianópolis/UFSC. CD-Rom dos Anais do Seminário Internacional Fazendo Gênero 7, 2006.

CITRON, M J. Gender and the Musical Canon. Cambridge: University Press, 1993. CUSICK, S. G. "Feminist Theory, Music Theory, and the Mind/Body Problem". Perspectives of New Music, Vol 32, Number 1 (Winter 1994).

DINIZ, E. Chiquinha Gonzaga: uma história de vida. Rio de Janeiro: Rosa dos Tempos, 1984.

HOLANDA, J.C. Eunice Katunda (1915-1990) e Esther Scliar (1926-1978): Trajetórias individuais e análise de sonata para piano 'Sonata de Louvação' (1960) e 'Sonata para Piano' (1961). Tese de Doutorado em Música do PPGM/UFRGS, 2006.

KRAMER, L.. Music as Culural Practice, 1800-1900. California: University of California Press: 1990.

MALUF, S. Sobre o mundo das Bruxas: A Bruxaria como Cosmologia in Encontros Noturnos: bruxas e bruxarias na Lagoa da Conceição. Rio de Jnaneiro: Rosa dos Tempos, 1993.

McCLARY, S. Feminine Endings. Minnesota: University of Minnesota Press, 1991. MELLO, M. I. C. Relações de Gênero e Musicologia: Reflexões para uma Análise do Contexto Brasileiro. In: Simpósio de pesquisa em música 3, 2006, Curitiba. Anais do Simpósio de pesquisa em música 3. Curitiba : DeArtes UFPR, 2006. p. 69-74.

SILVA, R M. da. O Universo Poético-Musical da Ratoeira - trabalho de conclusão do curso de Licenciatura em Música da Universidade Estadual de Santa Catarina. Florianópolis, 2005. 